\section{Original Article}

\section{Check for updates}

\section{OPEN ACCESS}

Received: Feb 21, 2017

Revised: Apr 25, 2017

Accepted: Apr 27, 2017

\section{Correspondence to}

Davide Inversini

Division of Surgery, Department of Medicine and Surgery, University of Insubria, Viale Borri 57,21100 Varese, Italy.

Tel: +39-0332-278450

Fax: +39-0332-260260

E-mail: davide.inversini@gmail.com

Copyright $($ C 2017. Korean Association of Thyroid and Endocrine Surgeons; KATES This is an Open Access article distributed under the terms of the Creative Commons Attribution Non-Commercial License (https:// creativecommons.org/licenses/by-nc/4.0/).

ORCID IDS

Gianlorenzo Dionigi (iD

https://orcid.org/0000-0003-0864-6087 Maria Laura Tanda (iD

https://orcid.org/0000-0001-7551-1751

Eliana Piantanida (iD)

https://orcid.org/0000-0002-2360-1621

Silvia Uccella (iD)

https://orcid.org/0000-0002-5714-7295

Davide Inversini (D)

https://orcid.org/0000-0002-4071-7706

Matteo Lavazza (D)

https://orcid.org/0000-0001-6467-3800

Vincenzo Pappalardo (D)

https://orcid.org/0000-0002-2050-3014

Fausto Sessa (D)

https://orcid.org/0000-0002-6633-536X

\title{
Cohexisting Medullary and Papillary Thyroid Cancer
}

\author{
Gianlorenzo Dionigi (1) ', Maria Laura Tanda (1) 2, Eliana Piantanida (1) ${ }^{2}$, \\ Silvia Uccella (ii) ${ }^{3}$, Stefano La Rosa ${ }^{4}$, Davide Inversini (1) ', Matteo Lavazza (1) ', \\ Vincenzo Pappalardo (i) ${ }^{1}$, Fausto Sessa (D) $^{3}$, Liu Xiaoli ${ }^{5}$
}

\author{
'Division of Surgery, Department of Medicine and Surgery, University of Insubria, Varese, Italy \\ ${ }^{2}$ Division of Endocrinology, Department of Clinical Medicine, University of Insubria, Varese, Italy \\ ${ }^{3}$ Division of Histopathology, Department of Medicine and Surgery, University of Insubria, Varese, Italy \\ ${ }^{4}$ Institute of Pathology, Lausanne University Hospital (CHUV), Lausanne, Switzerland \\ ${ }^{5}$ Division of Thyroid Surgery, Jilin Provincial Key Laboratory of Surgical Translational Medicine, China-Japan \\ Union Hospital of Jilin University, Changchun, China
}

\section{ABSTRACT}

Purpose: Papillary thyroid carcinomas (PTCs) and medullary thyroid carcinomas (MTCs) have always been considered different in terms of their incidence rates, cell origins, and histopathological features. Simultaneous occurrence of both disease entities is very rare. Methods: We describe a series of cases with simultaneous MTC and PTC occurrences in the thyroid gland.

Results: From 2,897 patients (mean age, 49.2 \pm 12.5 ; $81 \%$ women) who underwent thyroidectomy for cancer between 2000 and 2015, we reviewed 11 cases of simultaneous occurrence of MTCs and PTCs. Multifocal PTC with simultaneous MTC was detected in 5 of the 11 cases (45\%). Of these PTC patients, 2 had 2 foci, 2 had 3 foci, and 1 had 4 foci. There was 1 case of multifocal MTC with solitary PTC. One patient presented with "composite thyroid carcinoma" with mixed features of MTCs and PTCs. Eight patients $(72 \%)$ presented an association with diffuse lymphocytic thyroiditis. The sizes of the tumors were $1.95 \pm 0.23 \mathrm{~cm}$ vs. $1.20 \pm 0.20 \mathrm{~cm}$ for PTCs and MTCs, respectively $(\mathrm{P}=0.531)$. The prevalence of extrathyroidal extension was $33.1 \%$ vs. $30.2 \%$ for PTCs and MTCs, respectively ( $\mathrm{P}=0.282$ ). All patients underwent total thyroidectomy and central neck node dissection. Radio iodine was delivered to $44 \%$ of patients. Follow-up review revealed 9 disease-free patients and 1 with local neck recurrence, while 1 patient died due to non-thyroid reasons.

Conclusion: There are only 30 reports describing a total of 50 cases in the English literature regarding concurrent PTC and MTC in the same gland. This study represents one of the largest case series. Whether the incidence of another cancer in these patients is coincidental, or due to the possible activation of a common tumorigenic pathway for both follicular and parafollicular thyroid cells, remains to be elucidated.

Keywords: Carcinoma, papillary; Carcinoma, medullary; Thyroid neoplasms; Synchronous neoplasms; Complications; Therapy

\section{INTRODUCTION}

Papillary thyroid carcinoma (PTC) is the most common histological type (75\%-80\%) (1). It derives from the follicular cells of the median endodermal enlargement from the tongue (1). 
Author Contributions

Conceptualization: Gianlorenzo Dionigi, Maria Laura Tanda, Eliana Piantanida, Silvia Uccella, Stefano La Rosa, Davide Inversini, Matteo Lavazza, Vincenzo Pappalardo, Fausto Sessa, Liu Xiaoli; Data curation: Stefano La Rosa, Davide Inversini; Formal analysis: Vincenzo Pappalardo, Fausto Sessa, Liu Xiaoli; Investigation: Vincenzo Pappalardo, Fausto Sessa, Liu Xiaoli; Methodology: Maria Laura Tanda, Eliana Piantanida, Silvia Uccella, Stefano La Rosa; Project administration: Gianlorenzo Dionigi; Resources: Fausto Sessa; Software: Matteo Lavazza; Supervision: Gianlorenzo Dionigi; Validation: Gianlorenzo Dionigi; Visualization: Gianlorenzo Dionigi; Writing - original draft: Gianlorenzo Dionigi; Writing - review \& editing: Gianlorenzo Dionigi.

Conflict of Interest

No potential conflict of interest relevant to this article was reported.
PTC produces thyroglobulins and thyroid hormones (1). Medullary thyroid carcinoma (MTC) represents only $5 \%-8 \%$ of thyroid cancers (2). MTC has a different embryological origin; it derives from parafollicular cells of the ultimobranchial body of the neural crest. MTC secretes calcitonin and other hormonal peptides, and is considered a part of the amine precursor uptake and decarboxylation system of the thyroid (2). MTC may occur either as a hereditary or as a nonhereditary entity. Hereditary MTC can occur either alone as the familial MTC (FMTC) or as the thyroid manifestation of multiple endocrine neoplasia type 2 syndromes (2).

PTC is characterized by the presence of papillae and specific cellular changes, such as epithelial cells situated on basal membranes covering stromal fibers and thin capillaries, round laminated calcifications (psammoma bodies), ground-glass nuclei, and cytoplasmatic pseudoinclusions (1). MTC is composed of solid nests and infiltrating formations of polygonal or spindle-shaped cells, oxyphilic small cells, and sometimes, anaplastic features. The presence of amyloidal deposits and positive immunohistochemistry usually confirms the diagnosis of MTC (2).

Patients with PTC have the highest 10-year relative survival rates (98\%). The prognosis of MTC is generally worse than PTC $(70 \%-80 \%)(1,2)$. PTC happens to be a multicentric tumor and tends to spread to the regional lymph nodes (LNs) in the early stage of the disease (1). In fact, PTC is associated with cervical LN metastases in 30\%-90\% of patients (1). FMTC is often multifocal and bilateral (2). The incidence of positive LNs correlates with the size of the primary lesion at the time of diagnosis; $60 \%$ of patients have positive LNs if the MTC is larger than $2 \mathrm{~cm}(2)$.

PTC and MTC have always been considered different from each other in terms of their incidence rates, cell origins, and histopathological features. The concurrent occurrence of both in the same patient is rare; in fact, there are only 30 reports describing a total of 50 cases in the English literature $(3,4)$. This report describes a series of 11 cases of this rare association and the different theories that can justify it. Unique pathological figures are presented.

\section{METHODS}

Under a protocol approved by the Institutional Review Board at University of Insubria, we performed a retrospective review of patients who underwent thyroid surgery in a 15-year period between April 2000 and February 2015 with a diagnosis of a primary lesion. Slides were re-reviewed by thyroid pathology sub-specialists. We collected information on patient demographics, nodule size, multifocality, extrathyroidal extension, extent of surgery, and LN metastasis. Solitary disease was defined as a single cancer identified in the entire thyroidectomy specimen; multifocal disease was defined as more than one cancer focus identified in either a single lobe or in both thyroid lobes; and bilateral/contralateral disease was defined as more than one cancer focus identified in both thyroid lobes. Data were analyzed using IBM SPSS Statistics, version 21.0 (IBM Corp., Chicago, IL, USA). Significance was defined as $\mathrm{P} \leq 0.05$. The study was ethically conducted in accordance with the Declaration of Helsinki. Written consent of these patients was obtained for publication.

\section{RESULTS}

From 2,897 consecutive patients (mean age, $49.2 \pm 12.5$ years; $81 \%$ women) who underwent thyroidectomy for cancer between 2000 and 2015, we identified and reviewed 11 cases of 
simultaneous occurrence of MTC and PTC, thus with an overall prevalence of $0.37 \%$ in the surgically treated patients (Table 1). Family history of PTC was present in 1 of the 11 cases $(9 \%)$. All cases were sporadic MTCs. No hereditary MTC was found in this series, both multiple endocrine neoplasia type 2A (MEN2A), multiple endocrine neoplasia type 2B (MEN2B) or FMTC based on specific germline mutation of rearranged during transfection (RET) protooncogene. There was no history of previous neck or mediastinal radiotherapy. Smoking habits were present in $10 \%$ of the cases. All cases were found incidentally by pathological analysis after surgery. Multifocal PTC with simultaneous solitary MTC was detected in 5 of the 11 cases (45\%), and included the familial PTC case. Of these PTC cases, 2 had 2 foci, 2 had 3 foci, and 1 had 4 foci. There was only 1 case of multifocal MTC with solitary PTC. One patient presented with "composite thyroid carcinoma" with mixed features of MTC and PTC found in the isthmus of the gland. The other 4 cases were distinct PTC and isolated MTC. Eight of the 11 cases (72\%) presented an association of these tumors with diffuse lymphocytic thyroiditis (LT). Some unique pathological features are presented in Figs. 1-3. The sizes of the tumors were $1.95 \pm 0.23$ $\mathrm{cm}$ for PTC vs. $1.20 \pm 0.20 \mathrm{~cm}$ for MTC $(\mathrm{P}=0.531)$ and the prevalence of extrathyroidal extension was $33.1 \%$ for $\mathrm{PTC}$ vs. $30.2 \%$ for MTC $(\mathrm{P}=0.282)$. All patients in this series underwent total thyroidectomy and central neck node dissection. Radioactive iodine (RAI) was delivered in $44 \%$ of the total patients. The incidence of LNs metastasis revealed by central LN dissection was slightly higher, albeit not indicative, for PTC invasiveness (22.4\% vs. $19.8 \%, \mathrm{P}=0.069)$. Current follow-up review revealed 9 disease-free patients $(81 \%)$. One patient $(9 \%)$ had pathological fine needle aspiration (FNA), and calcitonin-washout confirmed MTC recurrence on the left side of the lateral neck with calcitonin levels of $49.7 \mathrm{ng} / \mathrm{L}$ (reference, 2-10 ng/L) and carcinoembryonic antigen (CEA) serum levels of $2.1 \mathrm{mcg} / \mathrm{L}$ (reference, $0-2.5 \mathrm{mcg} / \mathrm{L}$ ). One patient died due to other non-thyroid-specific reasons.

Table 1. The clinical and histopathological characteristics of all 11 patients with simultaneous occurrence of medullary and PTCs

\begin{tabular}{|c|c|c|c|c|c|c|c|c|c|c|c|c|c|}
\hline $\begin{array}{l}\text { Case } \\
\text { No. }\end{array}$ & $\begin{array}{l}\text { Age }(y r) / \\
\text { gender }\end{array}$ & Familiarity & FNA & $\begin{array}{c}\text { Preoperative } \\
\text { CEA } \\
(0-2.5 \mathrm{mcg} / \mathrm{L})\end{array}$ & $\begin{array}{c}\text { Preoperative } \\
\text { calcitonin } \\
(2-10 \mathrm{ng} / \mathrm{L})\end{array}$ & $\begin{array}{l}\text { Type of } \\
\text { surgery }\end{array}$ & $\begin{array}{l}\text { Thyroid } \\
\text { histology }\end{array}$ & $\begin{array}{l}\text { Size \& side } \\
\text { tumor } \\
\text { (PTC/MTC) }\end{array}$ & $\begin{array}{l}\text { Extrathyroidal } \\
\text { extension }\end{array}$ & $\begin{array}{c}\mathrm{LN} \\
\text { metastasis }\end{array}$ & $\begin{array}{c}\text { RET } \\
\text { proto- } \\
\text { oncogene }\end{array}$ & $\begin{array}{c}\text { RAI } \\
\text { treatment } \\
(\mathrm{GBq})\end{array}$ & $\begin{array}{c}\text { Follow-up } \\
(y r)\end{array}$ \\
\hline 1 & $60 / F$ & - & Suspicious & - & 25 & $\mathrm{TT}+\mathrm{CND}$ & PTC, MTC & $\begin{array}{l}1.8 / \mathrm{R} \\
1.2 / \mathrm{R}\end{array}$ & + & $+($ PTC) & - & - & 2 \\
\hline 2 & $44 / F$ & - & PTC & - & 20 & $\mathrm{TT}+\mathrm{CND}$ & mPTC, MTC & $\begin{array}{l}1.7 / \mathrm{L} \\
1.1 / \mathrm{R}\end{array}$ & - & - & - & 3.7 & 8 \\
\hline 3 & $49 / F$ & - & PTC & - & 10 & $T T+C N D$ & PTC, MTC & $\begin{array}{l}1.9 / \mathrm{L} \\
1.3 / \mathrm{L}\end{array}$ & - & - & - & - & 6 \\
\hline 5 & $60 / F$ & + (PTC) & PTC & - & 64 & $\mathrm{TT}+\mathrm{CND}$ & mPTC, MTC & $\begin{array}{l}1.9 / \mathrm{L} \\
1.4 / \mathrm{L}\end{array}$ & + & $+($ PTC $)$ & - & 6.5 & 2 \\
\hline 6 & $50 / F$ & - & Suspicious & - & 5 & $\mathrm{TT}+\mathrm{CND}$ & PTC, MTC & $\begin{array}{l}1.6 / \mathrm{R} \\
1.4 / \mathrm{L}\end{array}$ & - & - & - & - & 8 \\
\hline 7 & $51 / F$ & - & MTC & 5.0 & 5 & $\mathrm{TT}+\mathrm{CND}$ & PTC, mMTC & $\begin{array}{l}1.9 / \mathrm{L} \\
1.1 / \mathrm{R}\end{array}$ & - & $+($ MTC $)$ & - & - & 3 \\
\hline 10 & $43 / M$ & - & PTC & - & 100 & $\mathrm{TT}+\mathrm{CND}$ & PTC, MTC & $\begin{array}{l}0.9 / \mathrm{R} \\
1.4 / \mathrm{R}\end{array}$ & + & - & - & - & 3 \\
\hline 11 & $49 / M$ & - & Suspicious & - & 39 & $\mathrm{TT}+\mathrm{CND}$ & mPTC, MTC & $\begin{array}{l}1.4 / \mathrm{L} \\
1.8 / \mathrm{R}\end{array}$ & - & $+($ PTC) & - & 5.5 & 1 \\
\hline
\end{tabular}

PTC = papillary thyroid carcinoma; FNA = fine needle aspiration; CEA = carcinoembryonic antigen; $M T C=$ medullary thyroid carcinoma; $L N=$ lymph node; $R E T$ $=$ rearranged during transfection; $\mathrm{RAI}=$ radioactive iodine; $\mathrm{TT}=$ total thyroidectomy; $\mathrm{CND}=$ central node dissection; $\mathrm{F}=$ female; $\mathrm{M}=$ male; $\mathrm{mPTC}=$ multifocal papillary thyroid carcinoma; $m$ MTC = multifocal medullary thyroid carcinoma; $R=$ right lobe; $L=$ left lobe; $I=$ isthmus. 


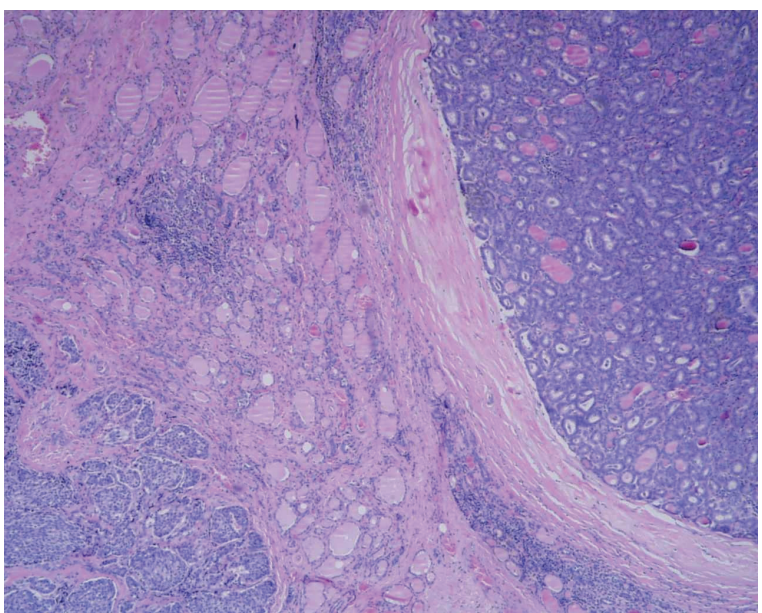

Fig. 1. Coexistence of (right) medullary and (left) papillary carcinoma with follicular aspects (H\&E, $\times 100)$. $\mathrm{H} \& \mathrm{E}=$ hematoxylin and eosin .

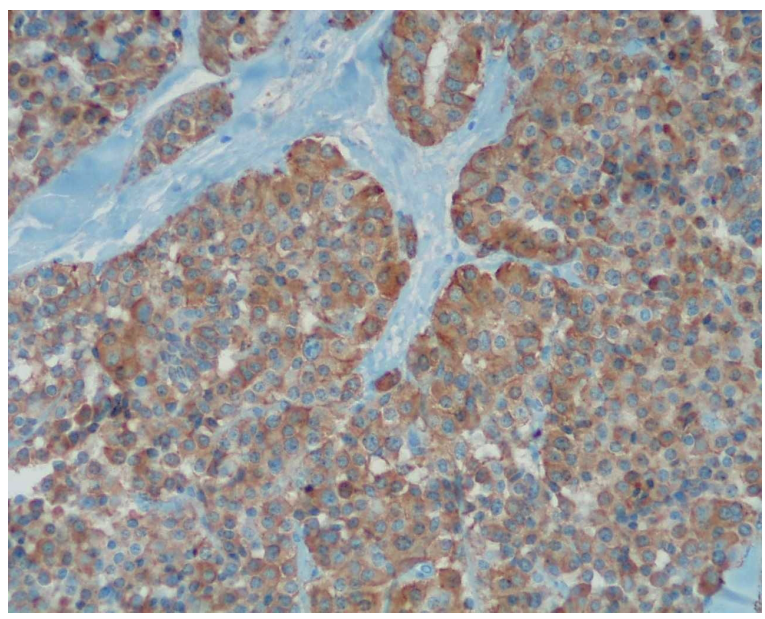

Fig. 2. Positive immunostaining reaction for CGRP and calcitonin (DAB-hematoxylin, $\times 400$ ). CGRP = calcitonin gene-related peptide; $D A B=$ diaminobenzidine.

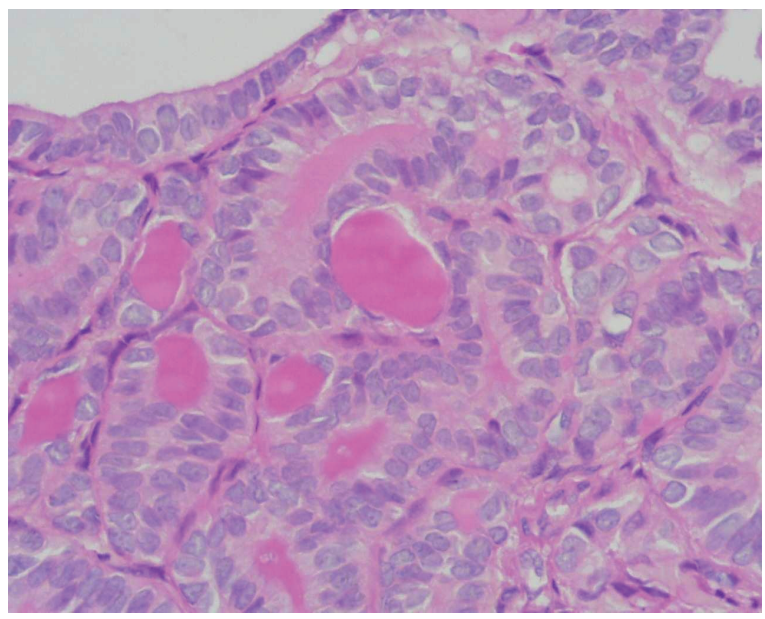

Fig. 3. PTC cells show overlapping clear nuclei and abundant eosinophilic cytoplasm (tall cell variant) (H\&E, $\times 400$ ). PTC = papillary thyroid carcinoma; H\&E = hematoxylin and eosin. 


\section{DISCUSSION}

MTC is a rare and aggressive type of thyroid cancer with several distinctive features that distinguish its management from PTC. Since MTC was first recognized as a distinct tumor in 1959, it became clear that MTC is more difficult to cure than PTC and has higher rates of recurrence and mortality $(1,2)$. In addition, unlike PTC, there is no known effective systemic therapy for MTC (2).

There are only 30 reports describing a total of 50 cases in the English literature describing the concurrent occurrence of both PTC and MTC in the same thyroid gland. This study represents one of the largest case series. The question remains as to whether the finding of another thyroid cancer in these patients was coincidental or from possible activation of a common tumorigenic pathway for both follicular and parafollicular thyroid cells. It is apparent that in the last decade, carcinoma of the thyroid is becoming increasingly prevalent. In fact, the incidence of thyroid carcinoma in Europe has increased during the period 1978-1997, by 3\% each year, largely due to PTC (1). In Italy, PTC is the most frequent thyroid cancer and shows a significant increase of incidence rates (1).

The pathogenesis of thyroid malignancy is unknown, but an underlying common genetic drive has been hypothesized. The process of thyroid oncogenesis is conceived to be a series of events induced by genetic and environmental factors that alter thyroid cell division and growth control. These factors can be considered as initiators and promoters (5). The first class of factors induce incipient tumorigenesis, while the second augment thyroid stimulating hormone (TSH) secretion and radically increase tumor growth (5). Normally silent, intracellular proto-oncogenes can become activated by chromosomal translocations, deletions, or mutations, and can transform normal thyroid cells into ones with uncontrolled division and growth (5). The most significant known cause of thyroid carcinoma is exposure to external or internal ionizing radiation (5). Several early events have been implicated in the neoplastic transformation of thyrocytes, and reports have described the involvement of specific genetic alterations in different types of thyroid neoplasms (5). The studies revealed that the RET proto-oncogene is involved in the oncogenesis of MTC and PTC by activation of tyrosine kinase either by point mutation or rearrangement (5). Activation of germline point mutations in the RET receptor is responsible for multiple endocrine neoplasia type 2-associated MTC, whereas somatic RET rearrangements are prevalent in PTC (5).

In the literature, there are 12 reports describing cases of mixed MTC and PTC $(3,4)$. Apel et al. (6) first proposed the term of "composite thyroid carcinoma." This can be explained if we consider the theory of a common stem cell, proposed by Ljungberg et al. (7). According to this theory, the ultimobranchial body is the most likely source of this putative common stem cell because the nests of these cells in the thyroid gland show immunoreactivity for both thyroglobulin and calcitonin, suggesting that the ultimobranchial body may contribute to both parafollicular and follicular cells $(6,7)$. In contrast to this theory, Volante et al. (8) proposed that the components of the 2 carcinomas are not derived from a single progenitor cell because they observed different patterns of RET proto-oncogene mutation (loss of heterozygosity and X-chromosomal inactivation) in many of these tumors. Furthermore, it has been presumed that there is a presence of unknown factors which are necessary for the stimulation of follicular cells, as well as the detection of these substances in the MTC of mixed medullary and follicular carcinomas and their absence in classical MTC has been noted (8). Recently, Rossi et al. (9) reported 3 cases of mixed MTC/PTC tumors in which 2 
mutations, in the RET and B-Raf proto-oncogene, serine/threonine kinase ( $B R A F)$ genes, were identified, thus documenting the different genetic origins of these 2 coexisting carcinomas.

Finally, PTC is often accompanied by LT, a phenomenon that may give rise to analyses of both pathogenetic mechanisms and prognostic implications (10). Coexisting LT has been shown to be associated with lower pT stages (10). Authors showed that apart from age (45 years or more), vascular invasion, and LN metastases, the absence of LT represents an independent prognostic indicator both for relapse-free and overall survival rates (10). Recently, Tamimi (10) reported that the prevalence of lymphocytic infiltrates is significantly higher in patients with PTC (58\%) than in patients with follicular carcinoma (20\%) or follicular adenoma (14\%); the possibility that an immunological mechanism involved in the pathogenesis of PTC stimulates lymphocytic infiltration in the thyroid tissue through an autoimmune mechanism was suggested. There are no data in the literature regarding the association of MTC and LT.

\section{REFERENCES}

1. Hu MI, Ying AK, Jimenez C. Update on medullary thyroid cancer. Endocrinol Metab Clin North Am 2014;43:423-42. PUBMED | CROSSREF

2. Maia AL, Wajner SM, Vargas CV. Advances and controversies in the management of medullary thyroid carcinoma. Curr Opin Oncol 2017;29:25-32. PUBMED | CROSSREF

3. Merchant FH, Hirschowitz SL, Cohan P, Van Herle AJ, Natarajan S. Simultaneous occurrence of medullary and papillary carcinoma of the thyroid gland identified by fine needle aspiration. A case report. Acta Cytol 2002;46:762-6. PUBMED | CROSSREF

4. Mazziotti G, Rotondi M, Manganella G, Franco R, Capone PFRS, Colantuoni V, et al. Medullary thyroid cancer, papillary thyroid microcarcinoma and Graves' disease: an unusual clinical coexistence. J Endocrinol Invest 2001;24:892-6. PUBMED | CROSSREF

5. Bounacer A, Wicker R, Caillou B, Cailleux AF, Sarasin A, Schlumberger M, et al. High prevalence of activating $R E T$ proto-oncogene rearrangements, in thyroid tumors from patients who had received external radiation. Oncogene 1997;15:1263-73. PUBMED | CROSSREF

6. Apel RL, Alpert LC, Rizzo A, LiVolsi VA, Asa SL. A metastasizing composite carcinoma of the thyroid with distinct medullary and papillary components. Arch Pathol Lab Med 1994;118:1143-7. PUBMED

7. Ljungberg O, Ericsson UB, Bondeson L, Thorell J. A compound follicular-parafollicular cell carcinoma of the thyroid: a new tumor entity? Cancer 1983;52:1053-61. PUBMED | CROSSREF

8. Volante M, Papotti M, Roth J, Saremaslani P, Speel EJ, Lloyd RV, et al. Mixed medullary-follicular thyroid carcinoma. Molecular evidence for a dual origin of tumor components. Am J Pathol 1999;155:1499-509. PUBMED | CROSSREF

9. Rossi S, Fugazzola L, De Pasquale L, Braidotti P, Cirello V, Beck-Peccoz P, et al. Medullary and papillary carcinoma of the thyroid gland occurring as a collision tumour: report of three cases with molecular analysis and review of the literature. Endocr Relat Cancer 2005;12:281-9. PUBMED | CROSSREF

10. Tamimi DM. The association between chronic lymphocytic thyroiditis and thyroid tumors. Int J Surg Pathol 2002;10:141-6. PUBMED | CROSSREF 